\title{
Accessible Digital Textbook for Learners with Disabilities: Opportunities and Challenges
}

\author{
Mary W. Wambaria \\ Kenya Institute of Curriculum development
}

How to cite this paper: Wambaria M.W. (2019). Accessible Digital Textbook for Learners with Disabilities: Opportunities and Challenges. The Educational Review, USA, 3(11), 164-174.

http://dx.doi.org/10.26855/er.2019.11.001

*Corresponding author: Mary W. Wambaria, Kenya Institute of Curriculum development.

Email: marywambaria@gmail.com

\begin{abstract}
The pilot study of the Accessibility Digital Textbook for learners in grade one was undertaken in March 2019.It was designed as a mixed methods study to investigate the opportunities and challenges of the Accessible digital textbook. The need to extend the provision of accessible formats to include digital learning resources (in addition to braille, audio, and large print) led to this study. An accessible digital textbook is a tool that allows all learners, including those with disabilities, to access information in alternative formats. While conventional teaching and learning resources are reasonably accessible to regular learners, they clearly present significant barriers for learners who have long-term physical, mental, intellectual or sensory impairments. In an effort to promote the dignity of learners with disabilities, there is need to harness information and communications technologies (ICT) to cater for their educational needs. One strategy to address this, is the use of appropriate augmentative and alternative modes, means and formats of communication, educational techniques and resources to support persons with disabilities. This article explores the benefits and challenges of developing an accessible digital textbook in relation to the VARK (Visual, Auditory, Read/Write, and Kinaesthetic) Learning style model. It is hoped issues raised in this paper will respond to a broad audience of different stakeholders engaged in either development or utilisation of digital accessible textbooks.
\end{abstract}

\section{Keywords}

accessible digital textbook, learners, disabilities, ICT, teaching and learning resources, curriculum

\section{Introduction}

One of the sustainable development goals is the provision of inclusive and equitable quality education and promoting lifelong learning opportunities for all (UN, 2015). Article 24 of the Convention on the Rights of Persons with Disabilities (CRPD) also articulates that all children can learn and should be given the opportunity to reach their full academic potential and therefore persons with disabilities should have the right to inclusive education, at all levels, without discrimination and on the basis of equality of opportunity(UN,2006). Despite the emphasis from these international conventions data indicates persons with a disability are among the population groups most likely to suffer from exclusion from education (United Nations Educational, Scientific, and Cultural Organization, 2018).

ICT is now an enormous part of everyday life. It is becoming vital that people from every sector of the community, including those with various disabilities and the consequent special needs, know how to make use of modern ICT and have the confidence to do so. Technology is often viewed as a promising intervention for diverse students to; gain access to the curriculum, foster engagement, and improve educational outcomes (Taylor \& Chacksfield, 2005; Hughes \& Talbott, 2017). It is therefore imperative that learners with disability are provided with an accessible digital textbook to enjoy the benefits of integration of technology in teaching and learning process. An accessible digital textbook is a tool 
that allows all learners, including those with disabilities, to access information in alternative formats. Accessibility is a critical key to leverage the power of technology and provide equal educational opportunity for all students, particularly those with disabilities. This concept involves the design of materials (e.g., curricula and resources), devices (e.g., smart phones and tablets), digital tools (e.g., computers, apps, and games), and platforms (e.g., online learning and websites) that support access to educational content and activities (Crossland, Gray, Reynolds, Wellington \& Zhou, 2016, p.2). Furthermore, accessibility refers to accommodating individual cognitive and physical needs to remove unnecessary obstacles so that students can demonstrate their knowledge and skills in formative and summative assessments.

The Government of Kenya has also stipulated in article 54 and 55 of the constitution that a person with any disability is entitled to use appropriate communication and access relevant education and training (Republic of Kenya, 2010). In addition to the constitutional provision, a policy for learners and trainees with disabilities have been developed, emphasing the need for adopting new technologies to improve learning and training in the targeted disability categories (Republic of Kenya, 2018). The Kenyan Institute of Curriculum development (KICD) in collaboration with United Nations Children's Fund (UNICEF) has embarked on an initiated to develop an Accessible Digital Textbook for Learners with Disabilities. The goal of this pilot project is to enhance the opportunities for disabled children to improve their learning outcomes by providing them access to the curriculum in multiple mediums.

\section{Statement of the Problem and Research Questions}

There is lack of rigorous and comparable data on disability and evidence on programmes that work can impede understanding and action (World health organization, 2011). Hughes \& Talbott (2017), also posits that a lack of research, especially what specific learning materials that are embedded in technologies that make a difference to enable diverse learners to close the achievement gap. In addition there is need to identify the nature and extent of those barriers that are keeping children with disability from attending school (UNICEF, 2014b). At the moment very little research has been conducted on the benefits and challenges of an accessible digital textbook. Researchers have recommended studies to focused on the opportunities and challenges of implementing Universal Design Learning(UDL) frameworks in a wide variety of learning environments across the age span by technology implementation and curriculum engagement for children and youth with deaf and blindness (Hartmann \& Weismer, 2016)hence the need for this research.

\section{Research questions}

1. To analyse the benefits of an accessible Digital textbook

2. To establish the challenges of using an Accessible digital textbook by learners with disabilities

\section{Literature Review}

More than one billion people in the world live with some form of disability, of whom nearly 200 million experience considerable difficulties in functioning (World Health Organization 2011). Persons with disabilities include those who have long-term physical, mental, intellectual or sensory impairments which in interaction with various barriers may hinder their full and effective participation in society on an equal basis with others. Disability is understood as an umbrella term to encompass impairments, activity limitations and participation restrictions (United Nations,2006; United Nations Children's Fund, 2014 a).

\section{Accessible Digital Textbook}

The definition of "accessible format copy" is fairly broad and covers any format that permits a person with a visual impairment or other print disability to have access to the content as feasibly and comfortably as a person without such a disability, including digital formats (World Intellectual Property Organization (WIPO),2017). According to Curry, Carl, \& Pérez (2018),accessibility refers to as "when a person with a disability is afforded the opportunity to acquire the same information, engage in the same interactions, and enjoy the same services as a person without a disability in an equally integrated and equally effective manner, with substantially equivalent ease of use. It guarantees a student with a disability is provided with curricular materials in needed formats, and technologies with required features, in a timely manner.Accessible materials are aimed at ensuring that people with disabilities can navigate, perceive, and understand content that takes into account the physical, visual, speech, auditory, neurological, and cognitive disabilities of the user(Gray\&Blackorby,2017).Accessible digital materials should adhere to the principles of Universal Design for learning(UDL).There is a growing awareness the supports necessary to ensure accessible learning can be built into the hardware and software at the inception of the development process. This approach is referred to as "born accessible" 
or universal design for learning (UDL) (Crosland et.al,2016).The UDL guidelines offer a set of concrete suggestions that can be applied to any discipline or domain to ensure that all learners can access and participate in meaningful, challenging learning opportunities (CAST, 2018). In curricula developed with the UDL Guidelines, materials provide multiple means of engagement; representation; and action and expression. In addition to materials, the UDL framework guides the design of instructional goals, assessments, and methods that can be customized and adjusted to meet individual needs.

\section{The Benefits of Accessible Digital Textbook in Learning}

Technology tools have become deeply entwined in the ways that we learn, work, communicate, play, and shop (Crosland et al., 2016). Instructional technologies play an important role in creating universally designed learning environments. Edyburn (2010b) highlights the key role of technology in the provision of universally designed environments, as a tool that can increase accessibility and engagement. Digital text inherently provides options where text can be converted easily to audio; can be displayed in different fonts, colours, and layouts on the screen; can be simplified as needed; and can be translated into other languages. This inherent flexibility allows digital text to be accessible to students with vision impairments, students with learning disabilities, students learning the language of instruction, and others who would simply prefer to modify or access text to suit their preferences.

Hughes and Talbott (2017), postulates that instructional technologies can provide flexible options for learning in a variety of way swallowing students to view information represented in various ways, express themselves creatively, and to engage in authentic and meaningful forms. For example, online environments can be designed with varied options built into the technology, allowing users to choose from a variety of supports such as text - to - speech, online glossaries, hyperlinks to related information and tools for note - taking and comprehension (e.g., highlighting tools). Technology can also provide means for students to express information in various creative formats, and consequently serve as non-traditional means of assessment. For example, instead of a written assessment to gauge a student's knowledge, students can use multimodal tools available on computers and mobile devices to express information orally or visually (e.g., audio or video recordings). These options can be useful for learners who benefit from having alternatives to written expression of knowledge.

Stahl (2004) and Crosland et al., (2016) outlines the benefits of accessible digital textbook as follows:

- Improves student learning -Accessibility features can help place your students with disabilities on an equal footing with their peers and focus their energies on learning, creating, and engaging with high-quality content.

- For learners with visual impairment and low vision the accessible digital textbook would increase the quality of braille-compliant digital files and significantly accelerate the delivery of alternate format materials to students with visual impairments.

- For students with physical disabilities, a more unified approach will allow for the creation of varied, well-structured and complete student-ready versions, including easily navigable digital files with images, from the same source file, eliminating redundancies and simultaneously improving the accuracy of the alternate version and aligning it with the print work. There are a number of physical disabilities that can also be aided through digital innovations for those with motor and coordination disabilities who have trouble turning a page or holding a book. A basic e-reader orphone with touch screen technology can be used to turn a page with a simple touch.

- For students with learning disabilities, the availability of textbooks in accessible alternative formats suitable for representation via human or synthetic speech would significantly increase the independent use of these core curriculum resources by students with learning disabilities. In addition, captions improve literacy for struggling readers and promote comprehension and language development for struggling readers by reading the words on the screen and hearing the words spoken aloud.

- For students who are Deaf or hard of hearing. The increased availability of digitally-based standard textbooks provides the necessary foundation elements for the subsequent creation of learning resources that contain both signed and text versions of the same instructional content. In addition, captioning not only supports people with hearing disabilities, but also enhances the user experience for all users.

In conclusion, accessible, flexible alternate versions of core curriculum materials can increase engagement, attention and achievement by offering adjustable levels of complexity, novelty and mixed media. Technology can support much of the effort toward curriculum access, participation and progress. Technology increases independence, personal 
productivity and empowerment. It can facilitate the kinds of interactions that occasion instruction, and it can transform static curriculum resources into flexible digital media and tools. (Jackson, 2004; Stahl, 2004).

\section{Challenges of Using the Accessible Digital Textbook}

The use of inaccessible materials is one of the barriers to attending school for children with disability and if they cannot participate fully in the classroom they will be less motivated to attend (UNICEF,2014 b).The Kenyan Government aims at provision of learners and trainees with disabilities in all institutions of learning and training with quality specialized learning resources, assistive devices and technologies responsive to various categories of disabilities. For effective utilization of the accessible digital textbook teacher capacity is critical. According to Hughes \& Talbott (2017), one of the challenges is that teachers are untrained, unwilling, or unavailable. Many teachers cannot forfeit traditional pedagogical cultures: inflexible age - graded curricula and assessment frameworks to cater for diversity. Many teachers do not cater to the needs of those with disabilities and demand that they perform as regular students; at other times, they are taught a remedial curriculum or not taught at all (Human Rights Watch, 2013). In Kenya, the capacities for teachers in technology adoption in the schools and training institutions are low (Republic of Kenya, 2010).

CAST (2018) posits that all learners vary in their interests, how they perceive information, and how they physically interact with digital materials and technologies. The accessibility is determined by the user, as opposed to being one fixed set of formats or features. The functional skills required for using digital materials and technologies, including physical, sensory, and cognitive, vary widely within and across learners. According to CAST, 2018 \& Gray\& Blackorby, 2017 Learners require digital materials according to their disability as follows:

- Learners with auditory disability that is ;heard of hearing and deafness may not use audio content that lack captions and transcripts

- A student with low vision may need a high contrast white on black screen display but the same high contrast display could make reading more difficult for someone with a reading difficulty such as dyslexia.

- A student may proficiently navigate a tablet screen using finger swipes, pinches, and taps, while a student with motor challenges may need to use switch technology to access the same device.

- A student with a writing challenge such as dysgraphia needs speech recognition to write an essay, while another student with a learning disability uses text to speech to hear the essay read aloud while drafting it.

\section{Theoretical Framework}

This study was anchored on VARK (Fleming, 2006) learning style. VARK is an acronym for visual, Aural, Reading and Kinesthetic. Fleming (2006), discovered that visual students are more prone to use text and graphic in multimedia element. Aural student prefers using text and graphic and also audio application in multimedia element. While kinaesthetic students are more inclined to use text and graphic through assignments in which requires act or hands on work. That study also did are search on the tendency of students leaning style using senses on each mode (Fleming, 2006). Through the use of the Accessible digital textbook teachers can have capacity to create what Othman \& Amiruddin (2010) refers to as a learning process which stimulates students, in order to attract attention to the subject taught. VARK Learning style allows teachers to adjust based on the child's capabilities and learning style but without changing the learning purpose (UNICEF, 2014b; Sreenidhi \& Tay, 2017; Amiruddin \& Othman,2010).

\section{Methodology}

The Kenya Institute of Curriculum development (KICD) in collaboration with United Nations Children's Fund (UNICEF) embarked on a pilot project on developing an Accessible Digital Textbook for Learners with Disabilities. The goal of the pilot initiative was to enhance the opportunities for children with disabilities to improve their learning outcomes by providing them access to the curriculum in multiple mediums.

A mixed method research design was used where both quantitative and qualitative data was concurrently collected. The study was a pilot on an accessible digital textbook in environmental activities for grade 1 learners. The study involved five counties in Kenya. Purposive sampling was used to select 23 Primary schools in the five counties specialising with learners who were virtually impaired, Hearing impaired, physically impaired, autism and intellectually different. In each school teachers and learners of the different categories participated in the study. In a study conducted by Spooner (2014), a total of 12 students and 13 support personnel in Blind and low vision students were purposely sampled. 
In the collection of data, an observation schedule and teachers' questionnaire were used. The two instruments were administered in all the 23 schools. Quantitative data was analysed using excel and summarised using tables and figures while the qualitative data collected was analysed and summarised into themes according to the objectives of the study.

\section{Results and Discussion}

\subsection{Introduction}

This section presents results and discussion according to the objectives of the study. For each objective the results are presented using descriptive statistics. A presentation of the findings is also done and supported with excerpts from teacher's responses.

\subsection{Categories of the schools}

Twenty-three schools (23) were sampled from five counties in Kenya and participated in the study. Table 2 indicates the number of schools in five categories of disabilities as follows; Hearing Impairment (5), Virtually Impairment (1), Physically Impairment (3), Intellectually different (7) and Integrated schools (7). Learners of Grade one participated in the pilot. At least two teachers in each school responded to a questionnaire. According to the responses from the teachers at least twenty schools had digital learner's devices. Most of the devices (18) were laptops while the rest used the tablets. In sixteen schools the devices were provided by the Government under the Digital literacy programme while the rest were sourced from private organizations.

Table 2. Categories of the schools $(\mathrm{N}=23)$

\begin{tabular}{ll}
\hline Type of school & Number of schools \\
\hline Hearing Impairment & 5 \\
Virtually Impairment & 1 \\
Physical impairment & 3 \\
Intellectually Different & 7 \\
Integrated school & 7 \\
\hline
\end{tabular}

\subsection{Appropriateness of content}

After the learners interacted with the content, the teachers were required to indicate the extent and they agreed with the statements about the pilot Accessible digital textbook. A Likert scale was used as follows; Strongly agree (5), Agree (4), Not sure (3), disagree (3) and strongly disagree(1). Table 3 indicates the teachers' responses. The teachers also give their comments on the improvement of the content as follows:

- The content is long, detailed and most learners have low concentration span

- Content to be as simple as possible and use of less wording and should be precise

- To be activity based not theory based

- The grammar is correct, language used appropriate and is simple

- For the learners with hearing disability Kenya sign language (KSL)is best for the lower classes

- It is stimulating and motivational

- Majority of the learners in lower level do not understand English and local language should be used 
Table 3. Appropriateness of content $(\mathrm{N}=46)$

\begin{tabular}{|c|c|c|c|c|c|}
\hline & Strongly Agree & Agree & Not sure & Disagree & Strongly disagree \\
\hline $\begin{array}{l}\text { The content is adapted to the } \\
\text { category of the learners }\end{array}$ & $19.7 \%(9)$ & $76.1 \%(35)$ & $2.1 \%(1)$ & $2.1 \%(1)$ & - \\
\hline $\begin{array}{l}\text { The content is capable of } \\
\text { enhancing learning }\end{array}$ & $39.1 \%(18)$ & $21.8 \%(10)$ & $39.1 \%(18)$ & - & - \\
\hline $\begin{array}{l}\text { The language used in the content } \\
\text { has correct grammar }\end{array}$ & $34.8 \%(16)$ & $63.1 \%(29)$ & - & $2.1 \%(1)$ & \\
\hline $\begin{array}{l}\text { The language used in the content } \\
\text { is appropriate for the learner }\end{array}$ & $26 \%(12)$ & $26 \%(12)$ & $19.6 \%(9)$ & $15.3 \%(7)$ & $13.1 \%(6)$ \\
\hline
\end{tabular}

\subsection{Appropriateness of Multi-media elements}

The accessible digital textbook has basic multimedia elements such as; text, photos, Audio, Animation, Video, sound and illustrations. Multimedia elements help in creating the learning contents and make the learning experiences more meaningful (Leow \& Neo, 2014). It is necessary that the elements are organized correctly and the interactions between the various elements are combined in an efficient and optimum and arguments learning so that it is successful (Ozdamli \& Cavus, 2011). The teachers rated the multimedia components on the ADT using a likert scale as follows; Very good (5), Good (4), Average (3) and poor (2). Table 4 summarises the teachers' responses. As indicated in table 4 majority of the teachers confirmed the photos were clear, relevant, the sound, video, illustrations and text clear and harmonised as they rated them at either very good and good.

Table 4. Appropriateness of Multi-media elements $(\mathrm{N}=46)$

\begin{tabular}{|c|c|c|c|c|c|}
\hline & Very good & Good & Average & poor & Very poor \\
\hline $\begin{array}{l}\text { The photos are clear; (have sharp } \\
\text { images, correct proportion and colour } \\
\text { and are properly captioned) }\end{array}$ & $34.8 \%(16)$ & $43.5 \%(20)$ & $13 \%(6)$ & $8.7 \%(4)$ & - \\
\hline The photos are relevant to the content & $47.8 \%(22)$ & $52.2 \%(24)$ & - & - & - \\
\hline $\begin{array}{l}\text { The sound is clear;(audible no } \\
\text { background interference, is well paced } \\
\text { and relevant to the topics) }\end{array}$ & $32.7 \%(15)$ & $54.4 \%(25)$ & $10.8 \%(5)$ & $2.1 \%(1)$ & - \\
\hline $\begin{array}{l}\text { The sound is properly harmonized with } \\
\text { the text throughout the content }\end{array}$ & $45.6 \%(21)$ & $47.8 \%(22)$ & $6.6 \%(3)$ & - & - \\
\hline $\begin{array}{l}\text { The videos are clear;(sharp images, } \\
\text { good pace and logical flow) }\end{array}$ & $36.9 \%(17)$ & $56.6 \%(26)$ & $4.4 \%(2)$ & $2.1 \%(1)$ & - \\
\hline $\begin{array}{l}\text { The videos are relevant to the topic } \\
\text { areas }\end{array}$ & $45.6 \%(21)$ & $43.6 \%(20)$ & $10.8 \%(5)$ & - & - \\
\hline $\begin{array}{l}\text { All videos are properly harmonized } \\
\text { with the sound }\end{array}$ & $28.2 \%(13)$ & $52.2 \%(24)$ & $19.6 \%(9)$ & - & - \\
\hline $\begin{array}{l}\text { The videos are synchronized with the } \\
\text { text }\end{array}$ & $34.8 \%(16)$ & $56.4 \%(26)$ & $4.4 \%(2)$ & $4.4 \%(2)$ & \\
\hline $\begin{array}{l}\text { The illustrations are clear; (sharp } \\
\text { image, correct colour, correct } \\
\text { proportion, labelled and captioned) }\end{array}$ & $50 \%(23)$ & $41.3 \%(19)$ & $6.6 \%(3)$ & $2.1 \%(1)$ & \\
\hline $\begin{array}{l}\text { The text is properly harmonized with } \\
\text { the sound throughout the content }\end{array}$ & $43.4 \%(20)$ & $47.8 \%(22)$ & $4.3 \%(2)$ & $4.3 \%(2)$ & - \\
\hline
\end{tabular}


Teachers also gave the following comments in regard to the appropriateness of the multimedia content:

- The images should be enlarged to arouse curiosity

- The signing and video should be appropriately aligned

- The elements should be clear with good use of colour and mages aligned to the content

- The photos are relevant to the topics covered

- Some said there is good sound production, clear and audible while others felt that the sound should be increased

- The sound is properly harmonized with the text, does not distract learning and can easily follow

- The videos add more knowledge to the contents

- The videos are clear, harmonized and to the level of the learners. However a few areas need to be rectified

- The videos are well explained, depict real life situations. However some images are missing

- The sound is okay but some videos are a bit dark

- The videos are properly harmonized with the sound

- The videos are well harmonized with the text

- The illustrations are clear .However, some videos are not opening

In one of the special school for the intellectually different the head of the school expressed his feedback as follows:

The accessible digital textbook is the best so far as learning for learners with intellectual disabilities is concerned. This is because it captures all their attention and they sit for about two hours without even visiting the toilets while in the ordinary thirty minutes lesson, they keep on moving out. This makes the lesson learner centred as it is all fun. Learners will learn more in the lesson that they are fully involved and which is enjoyable. In our school, the two hours of learning was nothing but fun and the learners if allowed could have continued. Having not interacted with computer before, they learned how to operate them very fast and started enjoying the lesson. All of us were impressed by the fast rate of learning and therefore this makes this mode of teaching and learning the best.

To further corroborate on the appropriateness of the content, an observation schedule was administered by two researchers per school in a real classroom setting. The schedule had 5 likert ratings scale to rate the learners ability in navigating through the content as follows; With much ease (5),With ease (4), With some difficulty (3), With a lot of difficulty (2) and Completely unable (1). The results as shown in table 3 shows that generally majority of the learner sat $69.5 \%$ (32) are completely unable to read the text provided in the digital content. This is mainly due to the fact that for the majority of the learners at this age in grade 1, English is not their first language.

Table 3. Ability of the learners to navigate through the content $(\mathrm{N}=46)$

\begin{tabular}{lccccc}
\hline Task & $\begin{array}{c}\text { With much } \\
\text { ease } \%\end{array}$ & $\begin{array}{c}\text { With ease } \\
\%\end{array}$ & $\begin{array}{c}\text { With some } \\
\text { difficulty } \%\end{array}$ & $\begin{array}{c}\text { With a lot of } \\
\text { difficulty } \%\end{array}$ & $\begin{array}{c}\text { Completely } \\
\text { unable } \%\end{array}$ \\
\hline $\begin{array}{l}\text { Navigate through the } \\
\text { content }\end{array}$ & $15 \%(7)$ & $10.9 \%(5)$ & $28.3 \%(13)$ & $28.4 \%(13)$ & $17.4 \%(8)$ \\
$\begin{array}{l}\text { Can turn on and off } \\
\text { audio and video }\end{array}$ & $10.9 \%(5)$ & $28.3 \%(13)$ & $17.5 \%(8)$ & $28.1 \%(13)$ & $15.2 \%(7)$ \\
$\begin{array}{l}\text { Read the text provided in } \\
\text { the digital content }\end{array}$ & $0 \%(0)$ & $2.2 \%(1)$ & $6.6 \%(3)$ & $21.7 \%(10)$ & $69.5 \%(32)$ \\
$\begin{array}{l}\text { Identify and follow } \\
\text { videos in terms of speed }\end{array}$ & $2.1 \%(1)$ & $4.3 \%(2)$ & $19.6 \%(9)$ & $21.8 \%(10)$ & $52.2 \%(24)$ \\
\hline
\end{tabular}




\subsection{Competence of the teachers in using digital content in the teaching and learning process}

The competency based curriculum being implemented in Kenya at Early years education has identified digital literacy skill as one of the competences to be integrated to support learning. Several research studies have underscored the need for digital competences among teachers (Johannesen, Øgrim, \&Giæver, 2014). In order to fulfil these requirements, digital competence among teachers is essential. Teacher training in all fields should include advanced digital competence for teachers and their teaching, not concentrating only on ICT user skills of teachers. These topics should be part of both initial teacher training and in-service training (Ala-Mutka, Punie, \&Redecker,2008). This study rated the teacher's competences in using the digital resources. Figure 2 indicates that only $6.9 \%(3)$ are very competence, $42 \%(18)$ competent, $42 \%(18)$ have average competences and 2.3\%(1) has below average and not competent at all. One of the challenges teachers mentioned was that they were not trained to use the digital materials in the classroom. Others indicated it was time consuming to connect the devices for a lesson that lasts only 30 minutes. A study conducted by Clarke \& Zagarell, 2012 also indicated that the challenges of using technology by teachers are many where they are left with little support to effectively incorporate tools into their teaching practice. In addition, individual teachers may have limited ability to implement technology tools and limited time for training to integrate technology into existing classroom practices (Clarke \& Zagarell, 2012).

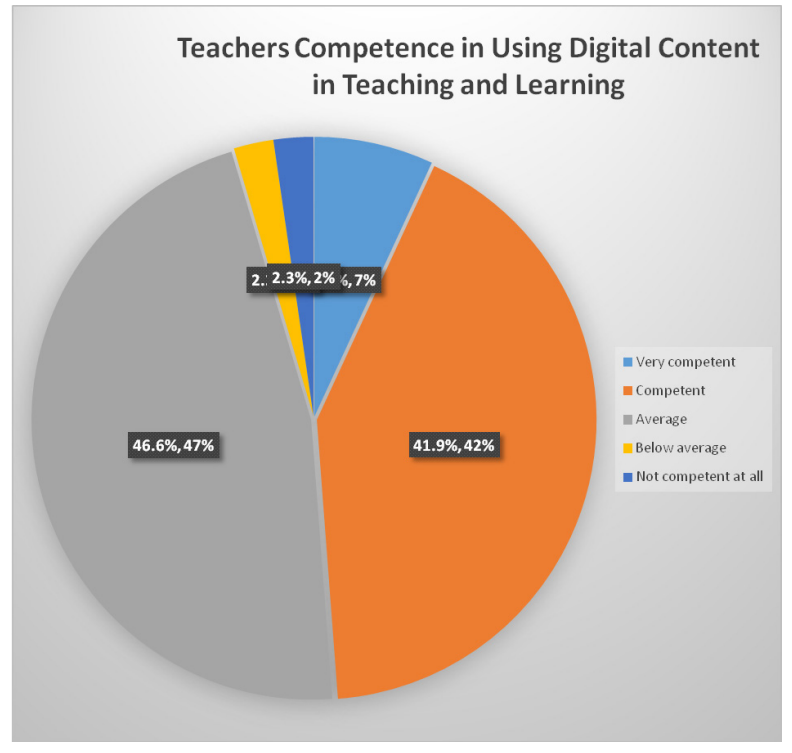

\subsection{The challenges of using the accessible digital textbook}

The study sought to find out the challenges learners and teachers faced in the utilization of the digital textbook. The information was obtained from teachers responses on the questionnaire and the observation schedule that the research teams used. Forty six teachers participated in the study. Two teachers in every school piloted filled the questionnaire. In each school there were two researchers who made observations and completed the observation schedule. Therefore in all the 23 schools there were a total of 46 observations.

Table 3 indicates the extent to which the learners are able to navigate through the content, turn on and off, read the text provided and follow the videos. Out of 46 observations only seven (7) group of learners were able to navigate the content with ease and eight (7) were completely unable. At least 13 could turn on and off audio and video with ease while six learners were also completely unable. None of the learners in the schools piloted were able to read the text provided in the digital content. This could have been due to the use of the English language which learners are not exposed to at this stage. Only nine (9) learners could Identify and follow videos in terms of speed although with some difficulty.

\section{Other challenges included:}

- There is diversity of learner's ability in class. Learners are not at the same pace of learning as some classes have both fast and slow learners 
- It is difficult to control a large class while using the digital devices

- Destruction of the devices by the learners. Some of the learners are hyperactive and keep touching the keyboard

- Accessibility of the devices when the teacher has a class .Most of the devices are kept in the head teachers office

- Poor connectivity and frequent power failures

- Malfunctioning digital devices

- Some classrooms are not connected to electricity while others are connected but lack enough sockets

- The language is not appropriate to the level of the learners.In some cases interpretation of the language is needed as the learners are not conversant with English language

- Some font sizes are not appropriate for learners with low vision

- Lack of appropriate software

- Lack of enough materials

- Inadequate ICT devices

Some of these challenges are consistent with a pilot study carried out that examined the benefits of providing curriculum materials in DAISY (Digital Accessible Information System) on Enhancing Text Accessibility for New Zealand Students, which was undertaken in 2008 and 2009(Spooner, 2014).In this study significant variables were identified as affecting the use of DAISY, including student preferences, abilities, and motivation; availability of DAISY text; reliability of and support for technology; and the provision of appropriate training in DAISY.

The teachers gave the following possible solutions to the challenges as follows:

- Content designers should involve the relevant stakeholders before coming up with the content.

- The content is not properly adopted for learners who are Intellectually Different.

- Provide power backup, improve on gadget hanging and use windows 7 as it is the most current.

- Translation of the language is needed for the learners are not conversant with English language.

- Enlarge font to cater for learners who are Virtually Impaired

- Assistance from teachers Aids, shortening of content, more captivating pictures and videos and deploy more teaching staff.

- Provide a short course and continuous training to all the teachers in handling and manipulating the digital textbooks and more time for the training

- Provide Wi-Fi to schools.

- Provision of hard copies as work books.

- Provision of adequate laptops and projectors

- Provide adequate time on the timetable for completion of lessons.

- Kiswahili should be introduced.

- Schools be provided with power backup

- Gadgets need to be enough to avoid scrambling

- Adaptation of devices for easier manipulation

- The keypads should be enlarged and the whole device as well

- Each child should have a gadget of his own (1:1)

- More sockets installed in the classrooms

- Provide a table of content on the digital textbook

- Explain words to the learners for clarity

- Learners should be given computer lessons. This will enable them to read on their own.

- When making the video a team of both hearing and deaf teachers to work together to harmonize the signs and also reduce on 'traditional' signs and learn more towards educational signs. 


\section{Conclusion}

The Accessible digital textbook provide a valuable adjunct to traditional accessible formats and should be a considered an option for students with visual, hearing and Intellectual impairments as part of their learning. However it is important to address the challenges of using an accessible digital textbook depending on the disability category

\section{Recommendation}

This study recommends production and dissemination of specialized learning resources and access to tax waivers on specialized learning resources and technologies for all learners and trainees with disabilities.

\section{References}

Ala-Mutka, K., Punie, Y., \& Redecker, C. (2008). Digital competence for lifelong learning. Institute for Prospective Technological Studies (IPTS), European Commission, Joint Research Centre. Technical Note: JRC, 48708, $271-282$.

Amiruddin \& Othman (2010). Different Perspectives of Learning Styles from VARK Model. International Conference on Learner Diversity 2010.

CAST (2018). Universal Design for Learning Guidelines version 2.2. Retrieved from http://udlguidelines.cast.org

Clarke, G., \&Zagarell, J. (2012). Technology in the classroom: Teachers and technology: A technological divide. Childhood Education, 88(2), 136-139. doi:10.1080/00094056.2012 .662140.

Crossland, Gray, Reynolds, Wellington and Zhou (2016). Digital Accessibility Toolkit: What Education Leaders Need to Know. Retrieved from http://www.ctdinstitute.org/sites/default/files/file_attachments/AccessibilityToolkit-508_ FINAL_100616.pdf

Curry, C., Carl, D., \& Pérez, P. (2018). Procuring accessible digital materials and technologies for teaching and learning: The what, why, who, and how. Wakefield, MA: National Center on Accessible Educational Materials.Retrieved from http://aem.cast.org/binaries/content/assets/common/publications/aem/procuringaccessibledigital.pdf

Crosland, Gray, Reynolds, Wellington, Zhou and Justo-Zavaleta (2016), Digital Accessibility Toolkit What Education Leaders Need to Know. Retrieved from https:/www.ctdinstitute.org/sites/default/files/file_attachments/ AccessibilityToolkit-508-FINAL 0.pdf

Edyburn, D. L. (2010b). Would you recognize universal design for learning if you saw it? Ten propositions for new directions for the second decade of UDL. Learning Disability Quarterly, 33, 33-41.In Hughes, M. T., \& Talbott, E. (Eds.). (2017). The handbook of diversity in special education. Retrieved from https://ebookcentral.proquest.com

Fleming, N. D. (2006). V.A.R.K Visual, Aural/Auditory, Read/Write, Kinesthetic. New Zealand: Bonwell Green Mountain Falls.

Gray,T. \& Blackorby,J. (2017).Digital Accessibility: What Educators Need to Know.32 ${ }^{\text {nd }}$ CSUN Assistive Technology Conference March 2, 2017.https://www.ctdinstitute.org/library/2017-03-01/32nd-csun-assistive-technology-conferencepresentation-andsupplementary?utm_source $=$ Copy + of + Bugaj+March $+\% 2$ B + Products\&utm_campaign $=$ Bugaj + March2 $+\% 26+$ Products\&utm_medium $=$ email.

Hartmann, E., \& Weismer, P. (2016). Technology implementation and curriculum engagement for children and youth who are deaf blind. American Annals of the Deaf, 161(4), 462-473.

Hughes, M. T., \& Talbott, E. (Eds.). (2017). The handbook of diversity in special education. Retrieved from https:// ebookcentral.proquest.com

Human Rights Watch. (2013). As long as they let us stay in class: Barriers to education for persons with disabilities in China. New York, NY: Human Rights Watch. Retrieved from https://www.hrw.org/2013/long/barriers-educationpersons-disabilities.

Johannesen, M., Øgrim, L., \&Giæver, T. H. (2014). Notion in motion: Teachers' digital competence. Nordic Journal of Digital Literacy, 9(04), 300-312.

Leow, F. T., \& Neo, M. (2014). Interactive multimedia learning: Innovating classroom education in a Malaysian university. Turkish Online Journal of Educational Technology-TOJET, 13(2), 99-110. 
Othman \& Amiruddin (2010).Different Perspectives of Learning Styles from VARK Model. Available online at www. sciencedirect.com

Ozdamli, F., \& Cavus, N. (2011). Basic elements and characteristics of mobile learning. Procedia-Social and Behavioral Sciences, 28, 937-942.

Republic of Kenya (2010). The constitution of Kenya

Republic of Kenya (2015). Sector Policy for Learners and Trainees with Disabilities

United Nations. (2006). Convention on the Rights of Children with Disabilities. Retrieved from http://uis.unesco.org/ sites/default/files/documents/ip49-education-disability-2018-en.pdf

United Nations Educational, Scientific, and Cultural Organization. (2018). Education and disability: analysis of data from 49 countries. Retrieved from http://uis.unesco.org/en/news/education-and-disability-analysis-data-49-countries

UNICEF (2014 a). Definition and Classification of Disability. Webinar Booklet 2

UNICEF (2014 b).Mapping Children with Disabilities out of School - Companion Technical Booklet Webinar 5

UN(2015).Sustainable development goals

Sreenidhi \& Tay, 2017. Styles of Learning Based on the Research of Fernald, Keller, Orton, Gillingham, Stillman , Montessori and Neil D Fleming. International journal for innovative research in multidisciplinary field ISSN - 24550620 volume - 3, issue - 4, Apr ., 2017

Stahl, S. (2004). The Promise of Accessible Textbooks: Increased Achievement for All Students. Wakefield, MA: National Center on Accessing the General Curriculum. (Links updated 2009). Retrieved from http://aem.cast.org/about/ publications/2004/ncac-accessible-textbooks.html

Spooner, S. (2014). "What page, Miss?" Enhancing Text Accessibility with DAISY (Digital Accessible Information System). Journal of Visual Impairment \& Blindness, 108(3), 201-211. https://doi.org/10.1177/0145482X1410800304

Taylor, N., \& Chacksfield, J. (2005). ICT for young people with SEN : A handbook for tutors. Retrieved from https:// ebookcentral.proquest.com

World Intellectual Property Organization (WIPO). (2017). Summary of the Marrakesh Treaty to Facilitate Access to Published Works for Persons who are Blind, Visually Impaired or Otherwise Print Disabled. Retrieved from https:// www.wipo.int/treaties/en/ip/marrakesh/summary marrakesh.html

World Health Organization (2011).Retrieved from https://www.who.int/disabilities/world_report/2011/accessible_en.pdf 